\title{
Practice
}

\section{Commentary: Think anaphylaxis}

BMJ 2009; 338 doi: http://dx.doi.org/10.1136/bmj.b846 (Published 09 March 2009) Cite this as: BMJ 2009;338:b846

\author{
Paul L A van Daele, consultant in internal medicine and clinical immunology \\ ${ }^{1}$ Departments of Internal Medicine and Immunology, Erasmus Medical Centre, Rotterdam 3015 GD, Netherlands
}

p.l.a.vandaele@erasmusmc.nl

Collapse is a commonly encountered problem in the emergency department. Its causes are many and varied, and some are potentially life threatening. 1 In this interactive case report, Mrs Barroso presented with recurrent collapses coinciding with the onset of menstruation.2 Given her rapid response to steroids, I would have thought initially that she had adrenal insufficiency. In fact, most of the respondents on bmj.com concluded the same.3 Based on the lack of response to vasoactive drugs, I would have discarded a diagnosis of anaphylaxis. Corticosteroids are usually effective only in preventing the biphasic or protracted reactions, and even this is questioned.4

\section{Wisdom of hindsight}

We were all wrong. Mrs Barroso did present with an anaphylactic reaction secondary to an underlying systemic mastocytosis. But could we have foreseen that we were wrong?

In retrospect we can. In the presentation of the case there were some clues that might have prompted the correct diagnosis. The diarrhoea and the flushing are unlikely symptoms in a patient with adrenal insufficiency but are common in anaphylaxis.

Confirmation of this diagnosis is relatively straightforward. Measurement of serum tryptase confirms or rules out mast cell activation. It is well known that the mast cell is the key effector cell in allergic reactions. Most anaphylaxis episodes are triggered through an immunological mechanism involving $\lg \mathrm{E}$. Anaphylaxis without identified IgE mediated allergies seems to be particularly prevalent in patients with (indolent) systemic mastocytosis. Insect venom, for instance, is known to cause histamine release by mast cells even in the absence of venom specific $\operatorname{lgE}$ in mastocytosis, and now we learn that menstruation can be a provocative factor as well.

Systemic mastocytosis is characterised by an accumulation of mast cells in one or more organs. The clinical course is variable. Many, but not all, patients present with typical skin lesions. Manifestations of the disease are provoked in large part by the resultant increase in mast cell derived mediators, which have a variety of local and systemic effects. 5 This makes systemic mastocytosis an intriguing disorder in which patients with essentially the same disease may present with various signs and symptoms to various specialists including dermatologists, allergists, haematologists, or gastroenterologists. 
What did I learn from this case? Foremost that timely measurement of serum tryptase levels in a patient with collapse and symptoms that might fit anaphylaxis, even in the absence of typical skin changes, can give a clue to the presence of a rare but perhaps sometimes overlooked diagnosis. Thereby additional unnecessary, invasive, and expensive diagnostic procedures can be avoided. But I am still puzzled by the lack of effect of intravenously administered dopamine and noradrenaline.

\section{Notes}

Cite this as: BMJ 2009;338:b846

\section{Footnotes}

- doi:10.1136/bmj.b246

- doi:10.1136/bmj.b247

- doi:10.1136/bmj.b799

- doi:10.1136/bmj.b796

- Competing interests: None declared.

\section{References}

1. Reed MJ, Gray A. Collapse query cause: the management of adult syncope in the emergency department. Emerg Med J2006;23:589-94.

2. Serrano Villar S, Perez-Somarriba J, Sainz Costa T, Winstanley S, Lopez TS, Gonzalez BO. A 38 year old woman with hypotensive shock at the onset of menstruation: case presentation. BMJ2009;338:b6.

3. Electronic responses. A 38 year old woman with hypotensive shock at the onset of menstruation: case presentation. BMJ 2009.www.bmj.com/cgi/eletters/338/feb09 1/b6 .

4. Lieberman P. Biphasic anaphylactic reactions. Ann Allergy Asthma Immunol2005;95:217-26; quiz 226, 258.

5. Valent P, Akin C, Escribano L, Födinger M, Hartmann K, Brockow K, et al. Standards and standardization in mastocytosis: consensus statements on diagnostics, treatment recommendations and response criteria. Eur $\mathrm{J}$ Clin Invest 2007; 37:435-53. 